\title{
Predictors of tobacco smoking among acutely ill patients in a Moscow hospital: A cross-sectional study
}

\author{
Aleksey Nadezhdin 1,2, Benedicte Joergenrud ${ }^{3}$, Elena Tetenova ${ }^{1}$, Evgeny Bryun ${ }^{1,2}$, Evgenya Koshkina ${ }^{1}$, Alexei Petukhov ${ }^{1,4}$, \\ Alexey Kolgashkin', Saranda Kabashi, ${ }^{3,5}$, Stig Tore Bogstrand ${ }^{3,5}$
}

\begin{abstract}
INTRODUCTION Tobacco smoking is a major preventable risk factor for noncommunicable diseases. The aim of this study was to investigate predictors of tobacco smoking among acute medically ill patients admitted to a Moscow hospital, and the association between smoking and alcohol use.

METHODS Patients admitted to the V. P. Demikhov hospital in Moscow from November 2016 through December 2017 were asked to participate in this study (inclusion criteria were acute medically ill patients aged $\geq 18$ years). Sociodemographic data were collected, in addition to questionnaires on mental distress (Hopkins Symptom Checklist 5), alcohol use (Alcohol Use Disorder Identification Test 4, AUDIT-4) and smoking (Fagerström Test for Nicotine Dependence).

RESULTS A total of 3009 patients were recruited to the study. Using a binary logistic regression model adjusted for all variables, it was found that living without a partner resulted in a higher risk of smoking tobacco compared to being married or living with a partner (odds ratio, $\mathrm{OR}=1.60$ for divorced, $\mathrm{p}=0.001$; and $\mathrm{OR}=1.62$ for single, $\mathrm{p}=0.002$ ), and being economically non-active resulted in a higher risk compared to being economically active $(\mathrm{OR}=1.47 ; \mathrm{p}=0.003)$. Harmful alcohol use (AUDIT- 4 score $\geq 5$ [for females] / 7 [for males]) resulted in a higher risk of smoking compared to those without harmful alcohol use $(\mathrm{OR}=4.04 ; \mathrm{p}<0.001)$. CONCLUSIONS Smoking was highly prevalent and associated with other adverse sociodemographic and lifestyle factors such as harmful alcohol use.
\end{abstract}

\begin{abstract}
AFFILIATION
1 Moscow Research and Practical Centre on Addictions, Moscow Department of Public Health, Moscow, Russia

2 Russian Medical Academy of Continuous Professional Education, Ministry of Health, Moscow, Russia 3 Department of Forensic Sciences,

Oslo University Hospital, Oslo, Norway 4 Sechenov First Moscow State Medical University, Moscow, Russia 5 Institute of Health and Society, Faculty of Medicine, University of Oslo, Oslo, Norway
\end{abstract}

CORRESPONDENCE TO

Benedicte Joergenrud. Department of Forensic Sciences, Oslo University Hospital, Sognsvannsveien 20, Oslo 0372, Norway.

E-mail: bemjoe@ous-hf.no

KEYWORDS

alcohol, smoking, Russia, tobacco cessation, somatic patients

Received: 17 October 2019 Revised: 17 January 2019

Accepted: 5 February 2020

\section{INTRODUCTION}

Chronic tobacco smoking is one of the leading preventable risk factors for non-communicable diseases, with immediate and long-term adverse health consequences such as cancer, cardiovascular disease, respiratory disease, and compromised immune system $^{1}$. In 2015 , there were reportedly 148.6 million disability-adjusted life years (DALYs: a measure of overall disease burden, expressed as numbers of years lost due to ill-health, disability or early death) attributable to smoking worldwide, resulting in adverse personal and population health effects, together with billions of dollars in lost productivity and healthcare costs ${ }^{2}$. In addition to the direct health consequences, it is estimated that smoking an average of 15.8 cigarettes daily reduces the lifespan by 6.5 years or 11 minutes of life per cigarette ${ }^{3}$. Globally, tobacco smoking is the cause of more than 6 million premature deaths annually ${ }^{4}$. Although smoking generally is declining worldwide, there are certain geographical regions where the prevalence remains high. The Global Adult Tobacco Survey (GATS) 2016 found that $49.5 \%$ of Russian men and $14.4 \%$ of Russian women used tobacco ${ }^{5}$, compared to $30 \%$ 
men and $7 \%$ women globally ${ }^{6}$, making the Russian Federation one of the highest tobacco-consuming countries in the world ${ }^{5}$. Other studies on smoking prevalence in the Russian population are relatively few and limited to the population of university students $^{7-9}$ and to inpatients at medical institutions ${ }^{10}$. At the same time, life expectancy for Russian men is much lower compared to other Western European men, with tobacco smoking being suggested as one of the primary reasons for this difference ${ }^{11}$. Tobacco use ranks among the top risk factors for total deaths and total DALYs in Russia ${ }^{12}$.

In response to the increasing number of smokingrelated deaths worldwide, the World Health Organization (WHO) has set out the Framework for Convention on Tobacco Control (FCTC), a treaty aimed at reducing smoking through regulatory strategies, and the MPOWER report that defines policies consistent with the $\mathrm{FCTC}^{13}$. Russian institutions and departments have implemented several measures aimed at reducing the consumption of tobacco products in the population ${ }^{14}$, entirely consistent with the visions of the WHO FCTC. These measures have yielded substantial results, reflected in a significant reduction in tobacco consumption in Russia in recent years ${ }^{15}$.

Smoking is a significant risk factor for noncommunicable diseases and is known to be highly correlated with other negative lifestyle factors such as consumption of psychoactive substances, especially alcohol ${ }^{16}$, and mental distress ${ }^{17}$. Although a few studies have investigated the prevalence among emergency-department patients, most of those studies found that prevalence among those patients is higher compared to the general population ${ }^{18-20}$. By reducing negative lifestyle factors such as tobacco smoking among patients admitted for acute medical illnesses, it is possible to lower the burden of non-communicable diseases on the healthcare system $^{21}$, reduce coronary heart disease mortality ${ }^{22}$, and improve quality of life $\mathrm{e}^{23}$. The departments of multidisciplinary clinics admitting patients can be crucial places in identifying individuals with tobacco addiction because of the increased focus on patient health and the lack of triggers associated with smoking in the hospital environment. Studies show that many patients who are smokers or have harmful alcohol consumption might experience a 'teachable moment' when they are admitted to hospital ${ }^{24}$, and so be willing to change their behaviour. However, unlike the use of alcohol, non-medicinal drugs, and illicit drugs, smoking is more socially acceptable, resulting in a significantly lower level of biased selfreporting. Subsequently, from a clinical perspective, the correlation between smoking and alcohol use would be of interest as daily smokers might be easier to identify than those with harmful alcohol use. Emergency medical department populations provide an excellent opportunity for screening and subsequent smoking cessation interventions.

The main aim of this study was to investigate sociodemographic and lifestyle predictors of tobacco smoking, and the association between smoking and harmful alcohol use, among acute medically ill patients admitted to the somatic departments of one of Moscow's multidisciplinary hospitals, as both smoking and harmful alcohol use are important risk factors for non-communicable diseases.

\section{METHODS}

\section{Participants}

A cross-sectional study was conducted at the V. P. Demikhov hospital in Moscow during a 1-year period (November 2016 through December 2017). The hospital is a multidisciplinary clinic with 972 beds and an annual hospitalization rate of about 60000 patients; the study inclusion areas were the southeastern districts of Moscow. Recruitment and interviews were performed by addiction doctors at the hospital, and the recruitment of patients was performed seven days and nights per week in the departments of internal medicine, neurology, pulmonology, and cardiology. The study was approved by the Local Ethical Committee of Moscow Research and Practical Centre on Addictions (Approval No. 04/2016 of 27.09.2016). Before inclusion, eligible participants were informed about the study, and those that agreed to take part provided a signed informed consent for participation. Inclusion criteria were acute medically ill patients aged $\geq 18$ years. Exclusion criteria were injury (as the reason for admission), non-Russian-speaking patients, or patients unable to provide informed consent for other reasons. To determine smoking status patients filled in self-reporting questionnaires, or, in the case of poor health condition, the questionnaire was filled 
in by the interviewer. The study was conducted anonymously, and the participant data were entered into the project database coded by an identification number. This study is part of a larger collaborative project between Oslo University Hospital and the Moscow Research Center on Addictions.

\section{Measures}

Self-reported questionnaires were completed for each patient, and data on gender and age were gathered. Socioeconomic factors such as partnership status (married/living with partner, LWP, divorced, single, or widowed) and occupational status (economically active, not economically active, including unemployed and disabled in working age, and retired) were recorded. To assess mental distress, the Symptom Checklist 5 (SCL-5) questionnaire was used ${ }^{25}$. SCL5 is a validated measure comprising 5 items extracted from the SCL-90 full version questionnaire, which was translated and previously used in a Russian population $^{26}$. In the present study, SCL-5 was used as a dichotomized variable with a cut-off score of $>2$, as an indicator of mental distress. Self-reported alcohol use was assessed using the Alcohol Use Disorders Identification Test 4 (AUDIT-4), which consists of the three first and tenth item of AUDIT ${ }^{27}$. On AUDIT-4, each item is given a score from 0 to 4 points, giving a total score ranging from 0 to 16 . We used AUDIT-4 total score as a dichotomized variable for detection of harmful alcohol use with a cut-off $\geq 7$ [m] for males and $\geq 5$ [f] for females ${ }^{28}$. AUDIT- 4 provides a continuous score reflecting risk and severity in alcohol use. In addition to using it as a dichotomized variable, AUDIT-4 was also divided according to the proportion of the WHO division of the full AUDIT into four zones reflecting different drinking patterns: zone 1 - low-risk drinking or abstinence (0-3 points); zone 2 - alcohol use in excess of low-risk guidelines (4-6 points); zone 3 - hazardous drinking (7-8 points); zone 4 - risky alcohol use and possible alcohol dependence ( $\geq 9$ points $)^{29}$. We applied these 'definitions' and modified divisions of zones from the full AUDIT (10 items) to our 4-item AUDIT-4 zones, bearing in mind that the full AUDIT scores range 0-40 points, whereas AUDIT-4 scores range 0-16 points. Also, to facilitate the patient's understanding of the 'standard drink' concept, a graphic aid was developed, visualizing the size of a single dose for the most common Russian alcoholic beverages (beer, dry wine, fortified wine, strong alcoholic beverages). The size of a single dose in the study was $10 \mathrm{~g}$ of absolute alcohol, as recommended by $\mathrm{WHO}^{29}$. Lastly, the patients were asked about their tobacco smoking behavior using a specially designed questionnaire. They were first asked about their experience with tobacco use. If the patient reported that he/she had never smoked or was not currently smoking (neversmoker), the questionnaire was not filled in any further. For patients who had previously smoked, but had quit for more than six months (quitters), then the time since quitting was recorded. If the patient was smoking at the time of data collection or stated that he/she quit smoking within the last six months, they were defined as smokers, and data on daily number of cigarettes, years of smoking and Fagerström test for nicotine dependence (FTND) was used to determine the severity of smoking dependence ${ }^{30,31}$. The FTND questionnaire is an internationally validated screening tool for nicotine dependence and consists of 6 items $\mathrm{s}^{30,31}$. The answers to each item are given points ranging from 0 to 1 or 0 to 3 , where the highest point reflects the highest degree of dependency, with 10 points being the highest total score. To achieve the objectives of the study, we applied the generally accepted division into 4 zones, corresponding to: zone 1 - low dependency (0-2 points); zone 2 low to moderate dependency (3-4 points); zone 3 - moderate dependency (5-7 points); and zone 4 high dependency ( $\geq 8$ points $)^{30}$.

\section{Data analysis}

Statistical analysis was performed using IBM SPSS Statistics 25.0, supplied by Predictive Solutions, the official supplier of IBM SPSS software products in Russia. Smoking status (and cessation) was used both as a dichotomous and categorical variable, AUDIT-4 was used as a dichotomous and ordinal variable, and FTND was used as an ordinal variable. Chi-squared test and binary logistic regression adjusted for all variables were used to investigate the association between smoking status (and cessation) and demographic variables, mental distress, and alcohol use. Linear-by-linear Association Test was used to investigate the association between AUDIT-4 zones and FTND zones. The level of significance was $\mathrm{p}<0.05$ for all statistical tests. 


\section{RESULTS}

In total, 91\% ( $\mathrm{N}=3009)$ of the eligible patients consented to take part in the study, and descriptive data, for the whole study group and for the study group divided into smoking status, are presented in Table 1 . The total prevalence of smokers among the patients was $31.6 \%$. There were marginally more women compared to men included in the study ( $52.9 \%$ and $47.1 \%$, respectively), and approximately half of the male patients were smokers (49.2\%) compared to $15.8 \%$ of the female patients, the difference being significant (chi-squared test $\mathrm{p}<0.001$ ). The proportion of smokers in each age group decreased with increasing age, with $53.4 \%$ of smokers in the youngest age group (18-40 years), and $6.3 \%$ in the

Table 1. Characteristics of the study sample admitted to a Moscow hospital, 2016-2017 ( $\mathrm{N}=3009)$

\begin{tabular}{|c|c|c|c|c|}
\hline Variables & $\begin{array}{c}\text { Total } \\
\text { n } \\
\text { (\% within } \\
\text { variable) }\end{array}$ & $\begin{array}{c}\text { Non smoker } \\
\text { In }(\%)\end{array}$ & $\begin{array}{c}\text { Smoker *. } \\
\text { n ( }(\%)\end{array}$ & $p^{a}$ \\
\hline Gender & & & & 0.000 \\
\hline Male & 1418 (47.1) & 720 (50.8) & 698 (49.2) & \\
\hline Female & 1591 (52.9) & 1339 (84.2) & 252 (15.8) & \\
\hline Age (years) & & & & 0.000 \\
\hline $18-40$ & $528(17.5)$ & 246 (46.6) & $282(53.4)$ & \\
\hline $41-60$ & 924 (30.7) & 493 (53.4) & 431 (46.6) & \\
\hline $61-70$ & 742 (24.7) & 556 (74.9) & $186(25.1)$ & \\
\hline$\geq 71$ & 815 (27.1) & 764 (93.7) & $51(6.3)$ & \\
\hline $\begin{array}{l}\text { Partnership } \\
\text { status }\end{array}$ & & & & 0.000 \\
\hline Married/LWP & 1457 (48.4) & 958 (65.8) & 499 (34.2) & \\
\hline Divorced & 398 (13.2) & 219 (55.0) & $179(45.0)$ & \\
\hline Widowed & $810(26.9)$ & 712 (87.9) & $98(12.1)$ & \\
\hline Single & 344 (11.4) & 170 (49.4) & $174(50.6)$ & \\
\hline $\begin{array}{l}\text { Employment } \\
\text { status* }\end{array}$ & & & & 0.000 \\
\hline Active & 897 (29.8) & $494(55.1)$ & $403(44.9)$ & \\
\hline Non-active & 491 (16.3) & 209 (42.6) & $282(57.4)$ & \\
\hline Retired & $1620(53.9)$ & 1355 (83.6) & 265 (16.4) & \\
\hline SCL-5* & & & & 0.001 \\
\hline$\leq 2$ & 2764 (92.1) & 1987 (71.9) & 777 (28.1) & \\
\hline$>2$ & $238(7.9)$ & $152(63.9)$ & $86(36.1)$ & \\
\hline AUDIT-4 zones* & & & & 0.000 \\
\hline $1(0-3)$ & 2214 (73.7) & 1792 (80.9) & $422(19.1)$ & \\
\hline $2(4-6)$ & $238(7.9)$ & $121(50.8)$ & 117 (49.2) & \\
\hline $3(7-8)$ & $123(4.1)$ & 33 (26.8) & $90(73.2)$ & \\
\hline 4 (9-16 points) & $429(14.3)$ & $112(26.1)$ & 317 (73.9) & \\
\hline
\end{tabular}

*Missing employment status on one patient, SCL-5 data on 7 patients, and AUDIT-4 data on 3 patients. ${ }^{* *}$ Smoking status: if smoking within six months prior to admittance, the patient was regarded a smoker. ${ }^{* * *}$ LWP: living with partner. a p-value based on chi-squared test. oldest age group ( $\geq 71$ years). Partnership status was found to be significantly associated with smoking, and almost half of the single and divorced patients $(50.6 \%$ and $45.0 \%$, respectively), $34.2 \%$ of married or cohabiting patients, and only $12.1 \%$ of widowed patients, were smokers. Among the economically non-active patients, $57.4 \%$ were smokers, while $44.9 \%$ of economically active patients and $16.4 \%$ of retired patients were smokers. The greatest proportion of smokers was found in the zone of risky alcohol use (9-16 points), with $73.9 \%$ being smokers, and the zone of hazardous alcohol use (7-8 points), where $73.2 \%$ identify as being smokers. The lowest proportion of smokers was in the zone of low-risk alcohol consumption or abstinence ( $0-3$ points), with $19.1 \%$ being smokers.

Binary logistic regression was used in order to investigate the association between smoking and demographic variables, mental distress, and alcohol use. The odds ratios (ORs) adjusted for all variables are depicted in Table 2 . There was a significant

Table 2. Binary logistic regression of factors related to current smoking status among patients who visited the hospital, Moscow 2016-2017

\begin{tabular}{|c|c|c|c|}
\hline Variables & Adjusted OR & $95^{\circ} \% \mathrm{CI}$ & p \\
\hline \multicolumn{4}{|l|}{ Gender } \\
\hline Male & Ref. & & \\
\hline Female & 0.298 & $0.241-0.368$ & 0.000 \\
\hline \multicolumn{4}{|l|}{ Age (years) } \\
\hline $18-40$ & Ref. & & \\
\hline $41-60$ & 0.862 & $0.660-1.126$ & 0.276 \\
\hline $61-70$ & 0.524 & $0.355-0.773$ & 0.001 \\
\hline$\geq 71$ & 0.142 & $0.087-0.233$ & 0.000 \\
\hline \multicolumn{4}{|c|}{ Partnership status } \\
\hline Married/LWP** & Ref. & & \\
\hline Divorced & 1.606 & $1.216-2.121$ & 0.001 \\
\hline Widowed & 1.143 & $0.829-1.577$ & 0.414 \\
\hline Single & 1.622 & $1.203-2.186$ & 0.002 \\
\hline \multicolumn{4}{|c|}{ Employment status } \\
\hline Active & Ref. & & \\
\hline Non-active & 1.469 & $1.138-1.897$ & 0.003 \\
\hline Retired & 0.802 & $0.582-1.105$ & 0.177 \\
\hline \multicolumn{4}{|l|}{ SCL-5 } \\
\hline$\leq 2$ & Ref. & & \\
\hline$>2$ & 1.406 & 0.994-1.989 & 0.054 \\
\hline \multicolumn{4}{|l|}{ AUDIT-4 } \\
\hline$<5[\mathrm{f}] / 7[\mathrm{~m}]$ & Ref. & & \\
\hline$\geq 5[\mathrm{f}] / 7[\mathrm{~m}]$ & 4.036 & $3.224-5.052$ & 0.000 \\
\hline
\end{tabular}

*Smoking status: if smoking within six months prior to admittance, the patient was regarded a smoker. ${ }^{* *}$ LWP: living with partner. $[\mathrm{f}]=$ for females, $[\mathrm{m}]=$ for males. 
association between gender and smoking, with a lower OR for women being smokers compared to men $(\mathrm{OR}=0.30 ; \mathrm{p}<0.001)$. Age was also significantly associated with smoking, with ORs of 0.52 and less for the two oldest age groups, using the age group $18-40$ years as reference $(p<0.01)$. Compared to married patients or patients living with a partner, divorced and single patients had higher ORs of being smokers $(\mathrm{OR}=1.61, \mathrm{p}<0.001$; and $\mathrm{OR}=1.62$, $\mathrm{p}=0.002$; respectively). Being economically nonactive was found to be significantly associated with smoking, compared to being economically active $(\mathrm{OR}=1.47 ; \mathrm{p}=0.003)$. The most marked association with tobacco smoking was noted in the group with harmful alcohol use according to the dichotomized AUDIT-4 score ( $\geq 5[\mathrm{f}] / 7$ [m]), compared to those with non-harmful alcohol use $(\mathrm{OR}=4.04 ; \mathrm{p}<0.001)$.

When asked about smoking status and cessation, $49.2 \%$ of all male patients responded that they were smokers (current smokers or had quit within the last 6 months), compared to $15.8 \%$ of all female patients, as shown in Figure 1. Approximately equal proportions of all male patients had either quit for $\geq 6$ months or never smoked $(27.6 \%$ and $23.2 \%$, respectively), while most female patients had never smoked $(73.5 \%)$ and $10.7 \%$ had quit $\geq 6$ months.
The results showed that the proportion of female smokers and quitters decreased with increasing age and that the proportion of female never-smokers increased with age. Comparatively, the proportion of male smokers tended to decrease with increasing age, while the proportion of male quitters increased with increasing age. However, the proportions of male never-smokers appeared to be comparable among the three youngest age groups and somewhat higher in the oldest age group (37.8\%). While there were more men compared to women in the two youngest age groups, and marginally more women in the age group 61-70 years, there were more than twice as many female patients in the oldest age group compared to male patients.

For the investigation of the relationship between nicotine dependence and alcohol consumption, a Linear-by-Linear Association Test was performed using FTND zones as the independent variable and AUDIT-4 zones as the dependent variable. It was found that over half of the patients with low nicotine dependence (1-2 FTND points) also had low alcohol consumption (0-3 AUDIT-4 points, $\mathrm{p}<0.001$ ), as shown in Figure 2. At the same time, over half of those with high nicotine dependence ( $\geq 8$ FTND points) also had risky use of alcohol (9-16 AUDIT-4

Figure 1. Smoking status and cessation (never-smoker, quitter, smoker) segregated by age group and gender

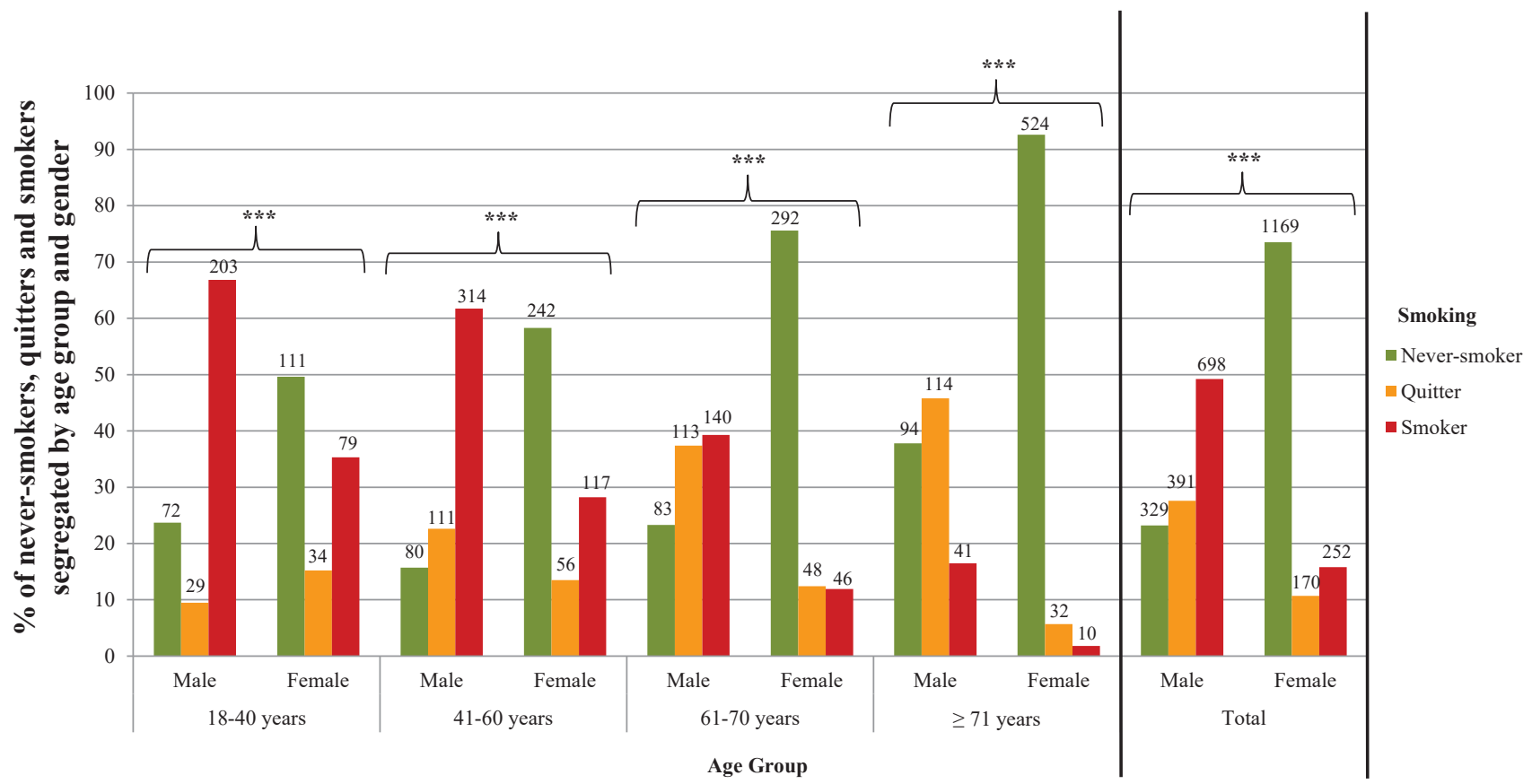

Number of patients depicted above each column. ${ }^{* * *}$ Chi-squared test $p<0.001$ between gender within the age group. 
Figure 2. The proportion of smoking patients segregated by FTND zones and AUDIT-4 zones

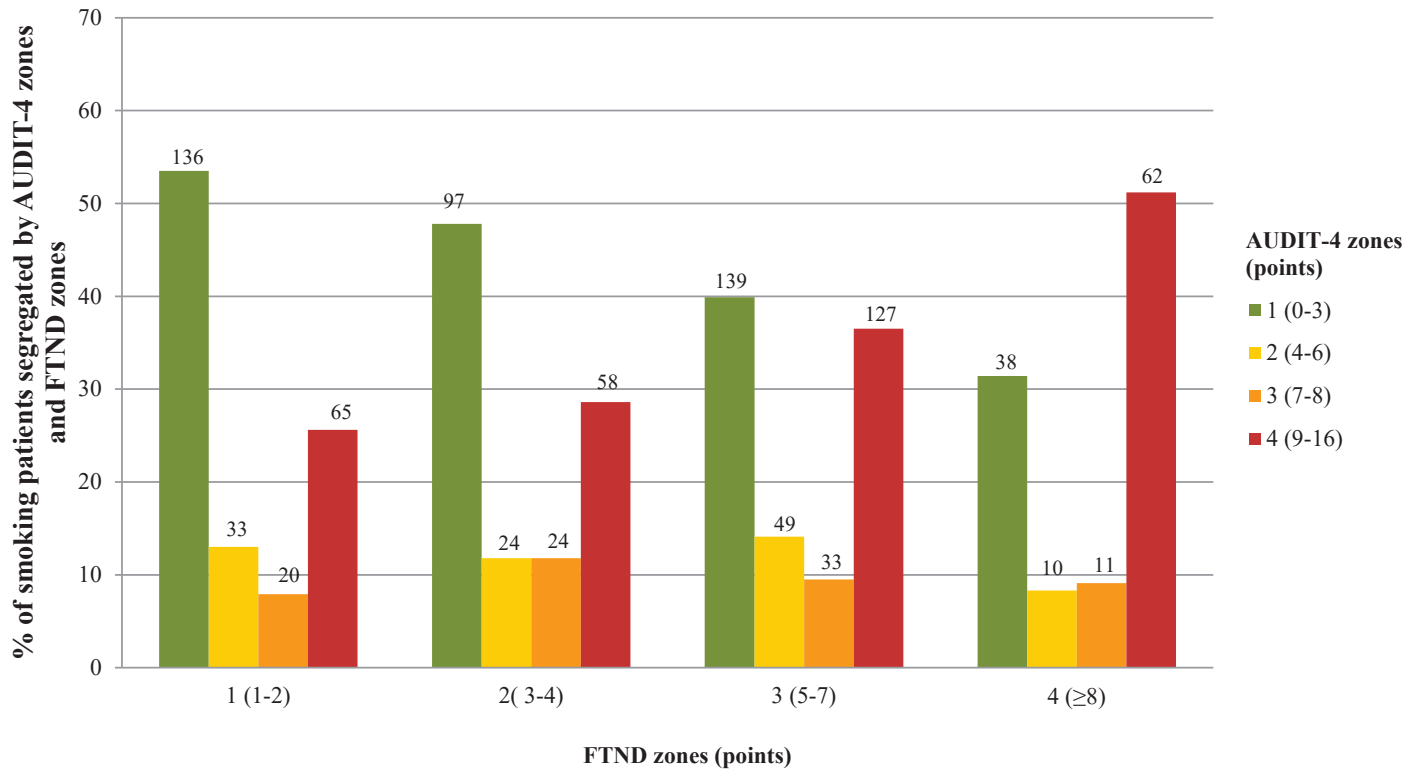

Number of patients depicted above each column. Linear-by-linear association test $p<0.001$.

points). A high proportion of individuals (with various degrees of nicotine dependence) had either low or high alcohol consumption.

\section{DISCUSSION}

In this study, comprising acutely ill patients admitted to V. P. Demikhov hospital in Moscow, we found that tobacco smoking was significantly associated with several factors such as partnership status, being economically non-active and having mental distress, while those with harmful alcohol use displayed four times higher odds ratio of smoking compared to those without harmful alcohol use.

The overall prevalence of smokers in this hospital population $(31.6 \%)$ was found to be approximately the same as the population prevalence in Russia, estimated at $30.5 \%$ in $2016^{5}$. These prevalences are about equal to what was found in previous studies investigating smoking prevalence among hospital patients. A hospital population comprising 399 Russian cancer patients found that $41.6 \%$ were smokers $^{32}$, indicating a higher prevalence compared to the general population, however smoking is a well-known significant risk factor for cancer. Also, among 335 Australian ED patients smoking prevalence was found to be $23 \%$, compared to $18 \%$ in the general population ${ }^{33}$. One explanation for the similar prevalences in our study and the general Russian population might be that our hospital population is older compared to the general population described in GATS, which might be due to the negative impact of tobacco use on individual life expectancy. Also, GATS showed that older adults generally believe that smoking causes serious illnesses ${ }^{5}$, which again might explain why fewer older adults smoke. The patients in the younger age groups (18-40 and 41-60 years) have a much higher prevalence of smokers compared to the younger age groups in the general population (15-24, 25-44 and 45-64 years $)^{5}$, indicating that smoking might have been a contributing factor for somatic illness in the younger patients.

The higher prevalence of male smokers in all age groups in our study is in concordance with what we know of global gender-differences in tobacco use ${ }^{34}$, especially in low- and middle-income countries ${ }^{13}$, and smoking is generally associated with sociocultural and economic factors ${ }^{35}$. Although tobacco advertisement is prohibited by law in Russia, it was found in GATS that a higher percentage of nonsmoking men compared to non-smoking women had noticed cigarette marketing during the last 30 days, especially in stores where cigarettes are sold and on the internet, and more women generally also 
believed that smoking caused illness ${ }^{5}$, which might explain the lower prevalence of female smokers in both our study and the general Russian population.

When investigating sociodemographic predictors, we found that smoking was significantly associated with partnership status, with a higher proportion of smokers being observed among single and divorced patients compared to patients that were married/ LWP. Other studies have found similar associations between smoking and partnership status ${ }^{36}$. One reason for higher smoking prevalence among single and divorced patients might be that smoking is a mechanism to cope with the psychosocial stress of living alone and different values concerning smoking. Smoking was found to be significantly associated with employment status, with a higher proportion of smokers among economically nonactive compared to economically active patients, similar to other studies ${ }^{37}$. As smoking results in more negative health consequences, this might be one of the reasons why there are more smokers among economically inactive patients. The lower proportion of smokers among the retired patients was not significant after adjusting for all other variables, presumably because of the high proportion of older women in this group.

Negative lifestyle factors, such as harmful alcohol use, were found to be significantly associated with smoking, in agreement with other studies on alcohol use and smoking ${ }^{38}$. The linear relationship between smoking dependence (FTND) and harmful alcohol use among patients underlines the importance of identifying these patients.

When examining smoking cessation between genders, we found that increasing proportions of men quit smoking with increasing age, compared to women. Women tend to be less likely to quit smoking, especially in the long-term, compared to men, but there are significant variations both regarding time-interval, geography and treatment/ non-treatment settings ${ }^{39}$.

Patients will have health benefits from smoking cessation, and admission to a hospital is an excellent opportunity to intervene, especially since the patient might be more motivated to stop smoking in this setting. A review of smoking intervention studies in hospitals found that high-intensity behavioral smoking cessation interventions initiated during the hospital stay, with prolonged contact after discharge, promoted increased smoking cessation rates ${ }^{40}$. In order to design effective programs for detection and subsequent psychological and medical treatment of tobacco-smoking patients, it is essential to know the sociodemographic portrait of this patient group, and its association to other negative lifestyle factors such as harmful alcohol use. It would be interesting to investigate the patient's motivation to reduce or quit smoking and alcohol use at admission to hospital, as this knowledge would be beneficial in developing comprehensive therapeutic interventions aimed at reducing both alcohol and tobacco use.

\section{Strengths and limitations}

The strength of the study was that it was conducted on a large population of acute medically ill patients in Moscow, using validated questionnaires and methods. Limitations are that face-to-face interviews about tobacco and alcohol use might lead to underreporting.

\section{CONCLUSIONS}

This study demonstrated that tobacco smoking is a widespread phenomenon among acute medically ill patients in Moscow, especially among younger patients, and that there is an association between harmful alcohol use and tobacco smoking among patients. Based on other studies, we believe that patients will be motivated and benefit from cessation interventions for smoking and alcohol use, at the hospital.

\section{REFERENCES}

1. West R. Tobacco smoking: Health impact, prevalence, correlates and interventions. Psychol Health. 2017;32(8):1018-1036. do i:10.1080/08870446.2017.1325890

2. GBD 2015 Tobacco Collaborators. Smoking prevalence and attributable disease burden in 195 countries and territories, 1990-2015: a systematic analysis from the Global Burden of Disease Study 2015. Lancet. 2017;389(10082):18851906. doi:10.1016/s0140-6736(17)30819-x

3. Shaw M, Mitchell R, Dorling D. Time for a smoke? One cigarette reduces your life by 11 minutes. BMJ. 2000;320(7226):53-53. doi:10.1136/bmj.320.7226.53

4. World Health Organization. WHO report on the global tobacco epidemic, 2013: enforcing bans on tobacco advertising, promotion and sponsorship. 2013. https://apps.who.int/ iris/bitstream/handle/10665/85380/9789241505871_ eng.pdf;jsessionid=9C239E5415DD30854B44A37D538 
68902? sequence=1. Accessed September 10, 2019.

5. World Health Organization. Global Adult Tobacco Survey. Russian Federation 2016. 2017. http://www.euro.who. int/en/countries/russian-federation/publications/globaladult-tobacco-survey-russian-federation-2016-factsheet. Accessed September 11, 2019.

6. Gowing LR, Ali RL, Allsop S, et al. Global statistics on addictive behaviours: 2014 status report. Addiction. 2015;110(6):904-919. doi:10.1111/add.12899

7. Bahtin Y, Suhorukov D, Sorokina L. [Prevalence of alcohol use and tobacco smoking among students of the pedagogical university] [Article in Russian]. Molodoj Uchenyj. 2014;14:267-270.

8. Shepeleva E, Esaulov V. [On the features of the combined use of alcohol and tobacco in young people aged 18 to 20 years] [Article in Russian]. Molodoj Uchenyj. 2018;1$1(187): 38-41$.

9. Tihomirova L, Basov A. [Modern research methods for attitudes regarding alcohol use and smoking among adolescents and students] [Article in Russian]. Yaroslavskij Pedagogicheskij Vestnik. 2015;4:152-156.

10. Makhov M, Nadezhdin A. [Clinical features of tobacco dependence in patients with alcoholism] [Article in Russian]. Narkologiya. 2016;15(1):39-50.

11. Bobak M, Marmot M. East-West mortality divide and its potential explanations: proposed research agenda. BMJ. 1996;312(7028):421-425. doi:10.1136/bmj.312.7028.421

12. Marquez P, Suhrcke M, McKee M, Rocco L. Adult health in the Russian Federation: more than just a health problem. Health Aff. 2007;26(4):1040-1051. doi:10.1377/hlthaff.26.4.1040

13. World Health Organization. WHO Report on the Global Tobacco Epidemic, 2011: The MPOWER package. Geneva, Switzerland: World Health Organization; 2012. https://apps.who.int/iris/ bitstream/handle/10665/44616/9789240687813_eng. pdf?sequence=1. Accessed September 13, 2019.

14. Lunze K, Migliorini L. Tobacco control in the Russian Federation-a policy analysis. BMC public health. 2013;13(1):64. doi:10.1186/1471-2458-13-64

15. World Health Organization. Global Adult Tobacco Survey (GATS) - Russian Federation 2009 and 2016. Geveva, Switzerland: World Health Organization; 2017. http:// www.euro.who.int/en/countries/russian-federation/ publications/global-adult-tobacco-survey-gats-russianfederation-2009-and-2016.-comparison-fact-sheet. Accessed September 11, 2019.

16. Batel P, Pessione F, Maitre C, Rueff B. Relationship between alcohol and tobacco dependencies among alcoholics who smoke. Addiction. 1995;90(7):977-980. doi:10.1111/j.1360-0443.1995.tb03507.x

17. Prochaska JJ, Das S, Young-Wolff KC. Smoking, Mental Illness, and Public Health. Annu Rev Public Health. 2017;38(1):165-185. doi:10.1146/annurev-publhealth-031816-044618

18. Boudreaux ED. Multicenter Study of Smoking, Nicotine Dependence, and Intention to Quit among Emergency Department Patients and Visitors. Acad Emerg Med. 2004;11(5):548-549. doi:10.1197/j.aem.2004.02.153

19. Boudreaux ED, Kim S, Hohrmann JL, Clark S, Camargo CA, Jr. Interest in smoking cessation among emergency department patients. Health Psychol. 2005;24(2):220224. doi:10.1037/0278-6133.24.2.220

20. Lowenstein SR, Tomlinson D, Koziol-McLain J, Prochazka A. Smoking habits of emergency department patients: an opportunity for disease prevention. Acad Emerg Med. 1995;2(3):165-171. doi:10.1111/j.1553-2712.1995.tb03189.x

21. Lightwood J, Glantz SA. Smoking Behavior and Healthcare Expenditure in the United States, 1992-2009: Panel Data Estimates. PLOS Medicine. 2016;13(5):e1002020. doi:10.1371/journal.pmed.1002020

22. Tverdal A, Thelle D, Stensvold I, Leren P, Bjartveit K. Mortality in relation to smoking history: 13 years' follow-up of 68,000 Norwegian men and women 35-49 years. J Clin Epidemiol. 1993;46(5):475-487. doi:10.1016/0895-4356(93)90025-V

23. Piper ME, Kenford S, Fiore MC, Baker TB. Smoking cessation and quality of life: changes in life satisfaction over 3 years following a quit attempt. Ann Behav Med. 2012;43(2):262-270. doi:10.1007/s12160-011-9329-2

24. Clark BJ, Moss M. Secondary prevention in the intensive care unit: does intensive care unit admission represent a "teachable moment?". 2011;39(6):1500-1506. doi:10.1097/CCM.0b013e31821858bb

25. Tambs K, Moum T. How well can a few questionnaire items indicate anxiety and depression? Acta Psychiatr Scand. 1993;87(5):364-367. doi:10.1111/j.1600-0447.1993.tb03388.x

26. Hoffmann C, McFarland BH, Kinzie JD, et al. Psychological distress among recent Russian immigrants in the United States. Int J Soc Psychiatry. 2006;52(1):2940. doi:10.1177/0020764006061252

27. Saunders JB, Aasland OG, Babor TF, de la Fuente JR, Grant M. Development of the Alcohol Use Disorders Identification Test (AUDIT): WHO Collaborative Project on Early Detection of Persons with Harmful Alcohol Consumption--II. Addiction. 1993;88(6):791-804. doi:10.1111/j.1360-0443.1993.tb02093.x

28. Gual A, Segura L, Contel M, Heather N, Colom J. Audit-3 and audit-4: effectiveness of two short forms of the alcohol use disorders identification test. Alcohol Alcohol. 2002;37(6):591-596. doi:10.1093/alcalc/37.6.591

29. World Health Organization. The Alcohol Use Disorders Identification Test. Guidelines for Use in Primary Care. Babor TF, Higgins-Biddle JC, Saunders JB, Monteiro MG. Geneva, Switzrland: World Health Organization; 2001. https://apps.who.int/iris/bitstream/ handle/10665/67205/WHO_MSD_MSB_01.6a. pdf? sequence $=1 \&$ cisAllowed=y. Accessed September 10, 2019. 
30. Heatherton TF, Kozlowski LT, Frecker RC, Fagerstrom KO. The Fagerstrom Test for Nicotine Dependence: a revision of the Fagerstrom Tolerance Questionnaire. Br J Addict. 1991;86(9):1119-1127. doi:10.1111/j.1360-0443.1991.tb01879.x

31. Fagerstrom KO. Measuring degree of physical dependence to tobacco smoking with reference to individualization of treatment. Addict Behav. 1978;3(3-4):235-241. doi:10.1016/0306-4603(78)90024-2

32. Schnoll RA, Engstrom PF, Subramanian S, Demidov L, Wielt DB, Tighiouart M. Prevalence and correlates of tobacco use among Russian cancer patients: implications for the development of smoking cessation interventions at a cancer center in Russia. Int J Behav Med. 2006;13(1):16-25. doi:10.1207/s15327558ijbm1301_3

33. Weiland T, Jelinek GA, Taylor SE, Taylor DM. Tobacco smoking by adult emergency department patients in Australia: a point-prevalence study. Public Health Res Pract. 2016;26(3):2631634. doi:10.17061/phrp2631634

34. Centers for Disease Control and Prevention. Cigarette smoking among adults and trends in smoking cessation - United States, 2008. In Morb Mortal Wkly Rep 2009:58(44)1227-1232. PMID:19910909.

35. Waldron I. Patterns and causes of gender differences in smoking. Soc Sci Med. 1991;32(9):989-1005. doi:10.1016/0277-9536(91)90157-8

36. Ramsey MW, Chen-Sankey JC, Reese-Smith J, Choi K. Association between marital status and cigarette smoking: Variation by race and ethnicity. Prev Med. 2019;119:4851. doi:10.1016/j.ypmed.2018.12.010

37. De Vogli R, Santinello M. Unemployment and smoking: does psychosocial stress matter? Tobacco control. 2005;14(6):389-395. doi:10.1136/tc.2004.010611

38. Anthony JC, Echeagaray-Wagner F. Epidemiologic analysis of alcohol and tobacco use. Alcohol Res Health. 2000;24(4):201-208. PMID:15986714.

39. Smith PH, Bessette AJ, Weinberger AH, Sheffer CE, McKee SA. Sex/gender differences in smoking cessation: A review. Prev Med. 2016;92:135-140. doi:10.1016/j.ypmed.2016.07.013

40. Rigotti NA, Clair C, Munafo MR, Stead LF. Interventions for smoking cessation in hospitalized patients. Cochrane Database Syst Rev. 2012;(5):CD001837. doi:10.1002/14651858.CD001837.pub3
CONFLICTS OF INTEREST

The authors have completed and submitted the ICMJE Form for Disclosure of Potential Conflicts of Interest and none was reported.

\section{FUNDING}

This work was supported by funding from the Norwegian Ministry of Health, for Norwegian-Russian collaboration in health and social issues (Grant B-1408). The Norwegian Ministry of Health had no role in the study design, data collection, analyses or interpretation, or in the writing of the report and the decision to submit the article for publication.

PROVENANCE AND PEER REVIEW

Not commissioned; externally peer reviewed. 